\title{
Management of Mesiodens In Mixed Dentition- Molariform and Tuberculate: A Case Report
}

\author{
Reena Augustine*, Prashant Babaji and Shashibhushan Kukkalli Kamalaksharappa \\ Department of Pedodontics And Preventive Dentistry, Sharavathi Dental College and Hospital, India
}

*Corresponding author: Reena Augustine, Department of Pedodontics And Preventive Dentistry, Sharavathi Dental College and Hospital, India

\begin{abstract}
Timely intervention is the key to any setback in the mixed dentition. Teeth which are supplemental to the normal dentition are supernumeraries, the most common being mesiodens, present in the premaxillary region. Certain pathological consequences may arise due to mesiodens like unaesthetic midline diastema, rotation, displacement, root resorption and cyst formation. The current case report presents the management of developing malocclusion in the anterior region due to the presence of mesiodentes- a molariform and a tuberculate. The molariform mesiodens was impeding the eruption of the maxillary right central incisor, thus the surgical removal of both mesiodentes was planned and executed. In addition to this soft tissue uncovering was done for the unerupted maxillary central incisor. On follow up, uneventful healing was observed successfully.
\end{abstract}

Keywords: Mesiodens; Mesiodentes; Mixed Dentition; Molariform; Tuberculate

\section{Introduction}

Supernumerary teeth, or hyperdontia, is a term that describes teeth that are surplus in number when compared to the normal complement of teeth [1]. The etiology of supernumerary teeth remains unclear and not yet completely understood [2]. Among the various proposed theories that have attempted to explain the causes behind the development of supernumerary teeth, current literature favors the 'lamina hyperactivity theory' that states hyperdontia results from independent, locally conditioned hyperactivity of the dental lamina [1]. The most commonly occurring supernumerary tooth is the 'mesiodens', a term that was initially coined by Balk in 1917. As the name suggests, the mesiodens is usually located mesial to the central incisors in the premaxillary region [3]. With a frequency of prevalence between $0.15-3 \%$ in the permanent dentition and $0.02-1.9 \%$ in the primary dentition, it may occur as single or multiple, unilateral or bilateral, may be erupted or impacted and frequently found in conjection with cleft lip and palate and syndromes like Cleidocranial dysostosis, Gardner's syndrome, Ellis-Van Creveld syndrome, Ehlers- Danlos syndrome, Incontinentia Pigmenti, and Tricia-Rhino- Phalangeal syndrome $[4,5]$. Also, mesiodentes may vary in shape from simple conical form to a larger, more complicated crown shape with several tubercles [6]. The dysfunctional nature of mesiodens is known to cause a variety of clinical complications such as being unaesthetic, pathological disturbances in the normal eruption and positions of adjacent teeth, altered growth and development in the area, retention of primary teeth, odontogenic cysts, caries, pulp necrosis of the adjacent teeth, dilaceration of developing tooth, nasal teeth, gingival and periodontal problems [2,7]. Accordingly, their early diagnosis and management is vital to waive off complications of such kind.

\section{Case Report}

A 9-year old female patient reported to the department of Pedodontics and Preventive Dentistry with the complaint of irregularly placed upper front teeth and wanted it to be corrected. The patient was normal and healthy with non-contributory medical and dental histories. The extra oral examination did not reveal any abnormalities. Intraoral examination revealed a Class I mixed dentition with a missing upper right central incisor and an erupted molariform mesiodens in its place. In addition, there was 
a firm bulge palpable in the upper right central incisor area which suggests the impediment in the path of eruption of the central incisor by the erupted mesiodens (Figure 1). An occlusal radiograph was taken to rule out the possibility of multiple supernumerary teeth and surprisingly another unerupted and impacted inverted mesiodens with an incomplete root was found mesial to the upper left central incisor (Figure 2). The SLOB technique confirmed that the impacted mesiodens was present palatially. Both informed and written consent was obtained from the parents before initiating the treatment. We decided to extract both mesiodentes under local anesthesia. The erupted mesiodens was extracted by intra- alveolar extraction. The impacted mesiodens was surgically removed by raising a mucoperiosteal flap from maxillary first premolar to contralateral first premolar (Figure 3). Rotary cutting instruments with simultaneous irrigation were used for removing enough bone around the impacted mesiodens for its easy retrieval. Soft tissue uncovering was done for the unerupted right central incisor by placing an elliptical incision over the incisal portion of the palpable bulge (Figure 4). The extraction socket was checked for any pathological tissue and the flap was relocated and sutured with interrupted sutures (Figure 5). The patient was recalled after a week for suture removal and followed-up after 3 months. Uneventful healing with no associated symptoms was observed.

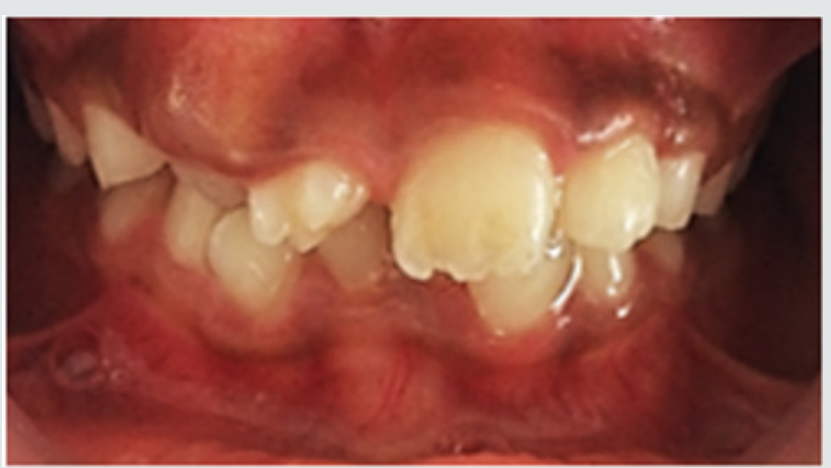

Figure 1: Preoperative view showing erupted molariform mesiodens along with unerupted maxillary central incisor.

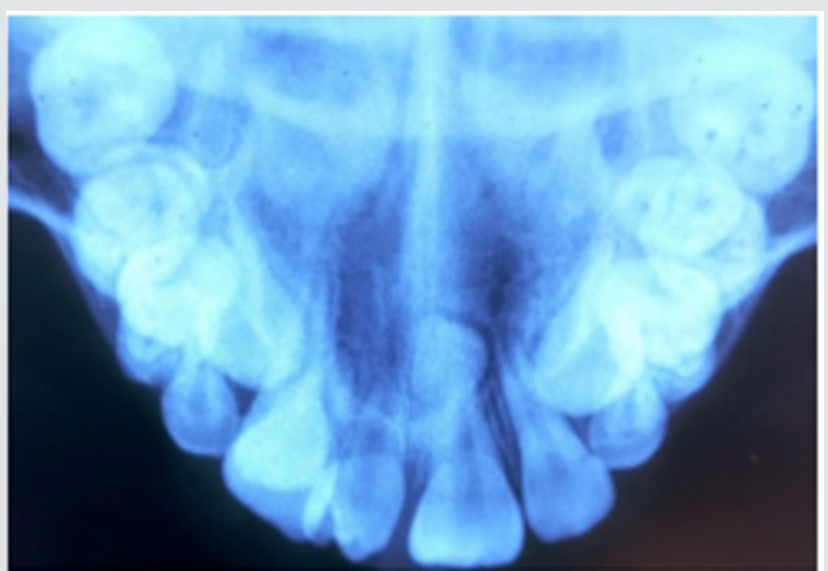

Figure 2: Occlusal radiograph showing unerupted and impacted inverted mesiodens with an incomplete root.

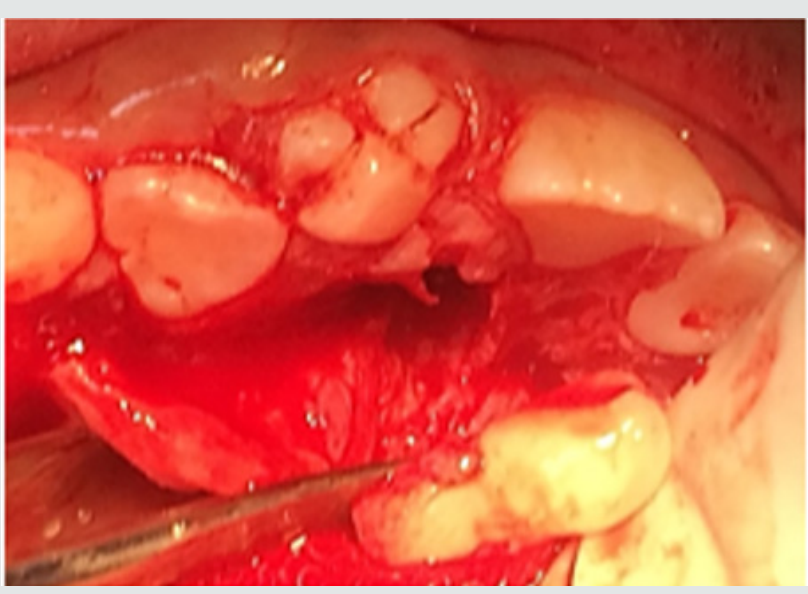

Figure 3: Surgical removal of impacted mesiodens by raising a mucoperiosteal flap from maxillary first premolar to contralateral first premolar.

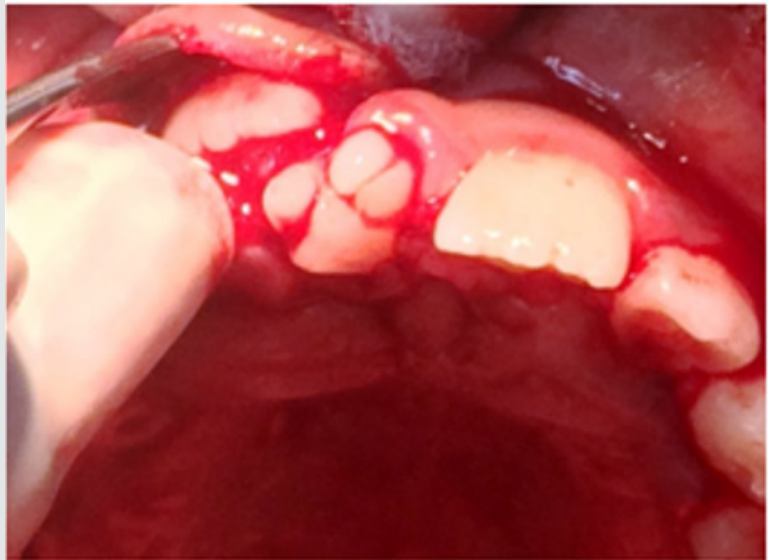

Figure 4: Soft tissue uncovering for the unerupted right central incisor by placing an elliptical incision over the incisal portion of the palpable bulge.

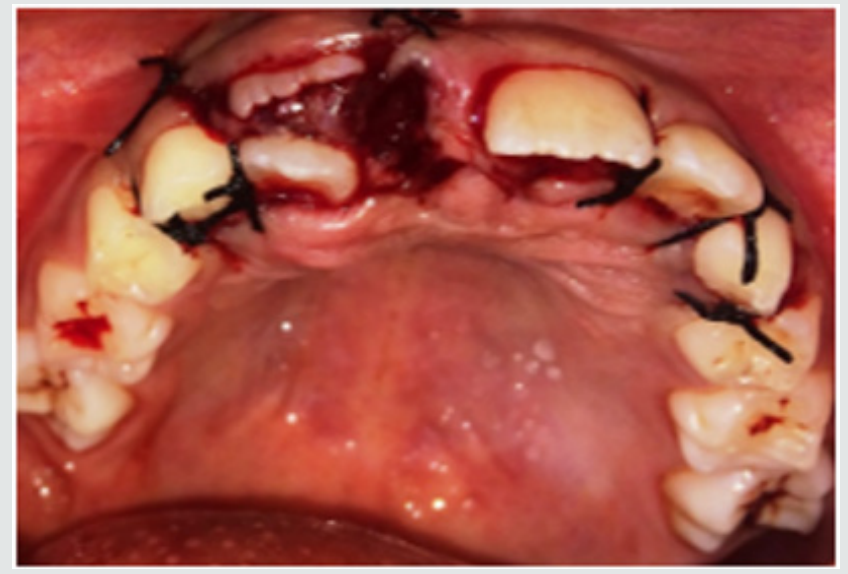

Figure 5: Interrupted sutures placed.

\section{Discussion}

The realm of pediatric dentistry incorporates the practice of interceptive orthodontics, thereby bestowing upon the pediatric dentist, opportunities of providing timely guidance in the development of occlusion. The current case report presents the 
management of developing malocclusion in the anterior region due to the presence of mesiodens. A mesiodens occurring in the primary dentition is a rarity even though, it being the most common dental abnormality in the permanent dentition [8]. Most cases of mesiodens are discovered during the first decade as maxillary central incisors are erupting and radiographic examinations are performed as an aid to screening for any other malformations and abnormalities [1]. Various theories regarding the etiology of mesiodens have been reported in the literature but the subject remains controversial [3]. Heredity has been suggested to be an etiologic factor based on the observation that supernumeraries are more common in family members; however, it does not follow a simple Mendelian pattern [9]. It was originally postulated that the mesiodens represented a phylogenetic relic of the extinct ancestors who had three central incisors. This is known as phylogenetic theory reversion (atavism) which has now been discarded by the embryologists [10]. The dichotomy theory states that, a mesiodens arises due to the splitting of the tooth bud. On the contrary, Taylor argued that splitting of the tooth bud may either form two equal sized teeth or one normal and one dysmorphic tooth [8]. The hyperactivity theory states that development of mesiodens is due to the hyperactivity of the dental lamina. The 'field model', proposes that a tooth bud which is forming at a given location develops according to its position within the field, further determining its shape. The 'clone model' postulates that that each tooth class is derived from a clone of ectomesenchymal cells which are programmed by epithelium to produce teeth of a given pattern. Depending upon the specific factors expressed from these ectomesenchymal cells, the shape of the accessory tooth germ forms in the vicinity of the incisors class of teeth becomes evident at the bell stage [11]. This case report presented with an erupted molariform mesiodens and an unerupted tuberculate mesiodens with an undeveloped root (Figure 6). Since the molariform mesiodens was impeding the eruption of the maxillary right central incisor, the surgical removal of both mesiodentes was planned and executed. Timing of interceptive treatment should be as soon as possible following clinical detection of an abnormal eruption pattern. It has been suggested that a tooth delayed in its eruption by more than six months with respect to its antimere should be radiographically investigated. Hogstrum and Andersson [12] suggested two alternatives exist.

The first option involves removal of the supernumerary as soon as it has been diagnosed. This could lead to an unpleasant experience that may have a psychological effect on a very young child and has been said to cause devitalization or deformation of adjacent teeth. Secondly, the supernumerary could be left until root development of the adjacent teeth is complete. The potential disadvantages associated with this deferred surgical plan include; loss of eruptive force of adjacent teeth, loss of space and crowding of the affected arch, and possible midline shifts. In the present case, since the roots of the adjacent teeth were completely formed and the child was at an age where she could sustain a surgical procedure, the surgery was undertaken with utmost attention to detail and caution. Access to mesiodens during surgery must dealt carefully considering the quantity of bone amputation and the possible damage to the adjacent teeth [7]. Follow up is indispensable in such cases since the eruption status should be monitored. The patient revealed satisfactory healing and suitable eruption of the maxillary central incisor. Pediatric dentists are the firsts to usually identify developing malocclusions and thus it is their responsibility to intervene and intercept in an apt manner to prevent future unfavorable sequalae.

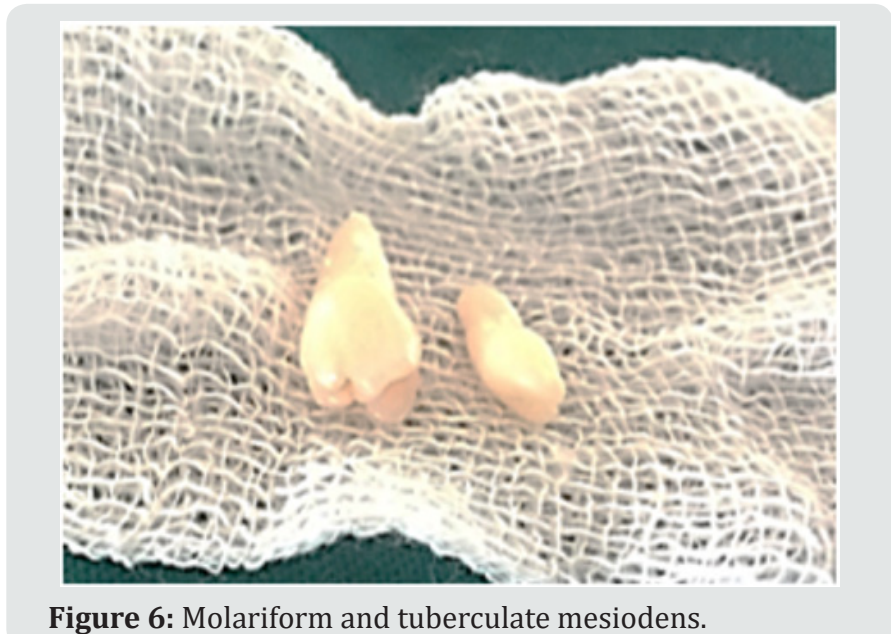

\section{Acknowledgements}

Authors are thankful to their colleagues and faculty.

\section{References}

1. Primosch RE (1981) Anterior supernumerary teeth-assessment and surgical intervention in children. Pediatr Dent 3(2): 204-215.

2. Jindal R, Sharma S, Gupta K (2012) Clinical and surgical considerations for impacted mesiodens in young children: An update. Indian J Oral Sci 3(2): 94-98.

3. Russell KA, Folwarczna MA (2003) Mesiodens-Diagnosis and management of a common supernumerary tooth. J Can Dent Assoc 69(6): 362-366.

4. Arathi R, Ashwini R (2005) Supernumerary teeth: A case report. J Indian Soc Pedo Prev Dent 23:103-105.

5. Mitchell L (1989) Supernumerary teeth. Dent Update 16: 65-69.

6. Seddon RP, Johnstone SC, Smith PB (1997) Mesiodentes in twins: a case report and a review of the literature. Int J Paediatr Dent 7: 177-184.

7. Sachin AG, Anand LS, Anil TP, Bhargav SS, Ankita RH, et al (2017) Management of Palatally Positioned Impacted Mesiodens: 2 Case Reports. J Orthod Endod 3: 1.

8. Rajab LD, Hamdan MA (2002) Supernumerary teeth: Review of Literature and a survey of 152 cases. Int J of Pediat Dent 12(4): 244-254.

9. Jasmin JR, Jonesco Benaiche N, Giamarchi MM (1993) Supernumerary teeth in twins. Oral Surg Oral Med Oral Pathol 76(2): 258-259.

10. Chaturvedi R, Kumar A, Kumar V (2012) Palatially impacted mesiodens-A case report. Indian J Dent Res Review, p. 54-56.

11. Ten Cate AR (2003) Oral histology. Development, structure and function. $\left(6^{\text {th }}\right.$ edn) St Louis Mosby, p. 76-77

12. Hogstrum A, Andersson L (1987) Complications related to surgical removal of anterior supernumerary teeth in children. J Dent Child 54(5): 341-343. 
CC (P) This work is licensed under Creative Commons Attribution 4.0 License

To Submit Your Article Click Here:

Submit Article

DOI: $10.32474 /$ IPDOAJ.2019.02.000143

\begin{tabular}{|c|} 
Interventions in Pediatric Dentistry \\
: Open Access Journal \\
Assets of Publishing with us \\
- Global archiving of articles \\
- Immediate, unrestricted online access \\
- Rigorous Peer Review Process \\
- Authors Retain Copyrights \\
- Unique DOI for all articles
\end{tabular}

